\title{
PENENTUAN JARAK TERPENDEK PADA JALUR DISTRIBUSI BARANG DI PULAU JAWA DENGAN MENGGUNAKAN ALGORITMA GENETIKA
}

\author{
I Dewa Made Adi Baskara Joni ${ }^{1}$, Vivine Nurcahyawati ${ }^{2}$ \\ ${ }^{1}$ STM IK STIKOM Indonesia, ${ }^{2}$ STM IK STIKOM Surabaya \\ E-mail : ${ }^{1}$ dewadi.414@gmail.com, ${ }^{2}$ vivine@stikom.edu
}

\begin{abstract}
Abstraksi
Terdapat banyak kemungkinan kombinasi jalur distribusi barang melalui darat yang dapat digunakan untuk mengoptimalkan waktu dan biaya perjalanan. Namun demikian, tidak semua kombinasi jalur distribusi tersebut akan memberikan solusi terbaik. Agar solusi terbaik dapat dicapai, suatu penelitian untuk menentukan jalur distribusi barang melalui jalur darat dilakukan. Untuk mempermudah proses penentuan jalur distribusi barang tersebut didukung dengan pembangunan perangkat lunak.

Algoritma genetika memiliki kehandalan dalam menghasilkan output yang optimal dapat dimanfaatkan untuk memecahkan masalah tersebut. Penerapan metode algoritma genetika diaplikasikan dalam suatu perangkat lunak. Pada perangkat lunak yang dibangun terdapat beberapa input yang dibutuhkan, yaitu: kota-kota tujuan distribusi sebagai jumlah kromosom awal, jumlah generasi, probabilitas crossover dan probabilitas mutasi. Hasil pemrosesan merupakan kombinasi jalur distribusi barang yang akan diambil yang merepresentasikan penyelesaian masalah ini. Hanya kromosom terbaik yang akan diberikan sebagai hasil. Melalui perangkat lunak yang dibangun, penentuan jalur distribusi barang diharapkan dapat dilakukan dengan lebih baik dan dapat mengoptimalkan waktu dan biaya perjalanan.

Berdasarkan penelitian yang telah dilakukan, digunakan 5 kombinasi kota sebagai tujuan distribusi yang digunakan pada pengujian. Melalui pengujian yang telah dilakukan terhadap tiga skenario didapatkan bahwa penerapan skenario pertama dengan nilai PC dan PM yang rendah (PC \& PM < 50). Skenario tersebut menghasilkan rute distribusi dengan nilai fitness yang lebih rendah daripada nilai fitness pada tahap inisialiasi data awal. Nilai fitness pada tahap inisialiasi dari kromosom adalah 931 dan setelah melalui proses algoritma genetika menghasilkan nilai fitness 762 .
\end{abstract}

Kata Kunci: Algoritma Genetika,optimasi waktu, biaya perjalanan, perangkat lunak

\section{Pendahuluan}

Distribusi adalah salah satu hal yang penting dalam suatu bidang usaha. Segala upaya diusahakan agar barang cepat sampai pada konsumen dan bisa diterima dengan baik. Dalam jurnal oleh Yanbin Liu (2010) dkk. [1] ditulis tentang adanya suatu software yang dibuat untuk mendukung keputusan top manajemen dalam hal transportasi laut. Dari enam modul yang ada, salah satunya adalah membahas tentang bagaimana mencari jarak terpendek pada jalur distribusinya. Mengacu pada jurnal tersebut maka akan dicoba penerapan algoritma genetika dalam jalur distribusi darat.

Algoritma genetika dapat dimanfaatkan pada masalah tersebut, karena memiliki kelebihan dalam menghasilkan output yang optimal. Dengan menggunakan konsep evolusi biologis maka akan dihasilkan suatu output berupa kombinasi jalur distribusi barang yang sebaiknya diambil untuk mengoptimalkan waktu dan biaya perjalanan. Untuk menerapkan algoritma genetika pada persoalan ini, dibuatlah perangkat lunak. Pada perangkat lunak yang dibuat, diinputkan beberapa kombinasi kota tujuan distribusi barang. Kemudian dilakukan pengujian perangkat lunak dengan parameter-parameter algoritma genetika yang bervariasi dan akan diketahui kromosom terbaik. 


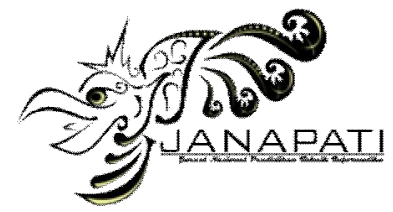

ISSN 2089-8673

Jurnal Nasional Pendidikan Teknik Informatika (JANAPATI)

Volume 1, Nomor 3, Desember 2012

Tujuan yang ingin dicapai dalam penelitian ini adalah untuk menentukan jalur distribusi barang yang terbaik dengan menggunakan algoritma genetika. Dalam penentuan jalur tersebut difokuskan pada pendistribusian barang ke agen-agen yang melalui jalur darat. Jalur distribusi yang digunakan dalam penelitian ini hanya yang ada dipulau jawa dan kota awal merupakan kota tujuan akhir dari jalur distribusi. Dalam penelitian ini, terdapat 5 kota yang menjadi input dalam satu jalur distribusi.

\section{Dasar Teori}

\subsection{Algoritma Genetika}

Algoritma genetika adalah algoritma pencarian heuristik yang didasarkan atas mekanisme evolusi biologis. Keberagaman pada evolusi biologis adalah variasi dari kromosom antar individu organisme. Algoritma ini didasari oleh konsep evolusi biologi, dan dapat memberikan solusi alternatif atas suatu masalah yang hendak diselesaikan. Algoritma genetika menawarkan suatu solusi pemecahan masalah yang terbaik, dengan memanfaatkan metode seleksi, crossover, dan mutasi [2].

Algoritma genetika adalah suatu bentuk teknik pencarian secara stochastic, berdasarkan mekanisme yang ada pada seleksi alam dan genetik secara natural. Algoritma genetika telah banyak diaplikasikan untuk penyelesaian masalah dan pemodelan dalam bidang teknologi seperti optimasi, pemrograman otomatis dan machine learning. Pada implementasi program algoritma genetika dapat digunakan untuk mencari jalan terpendek bebas hambatan. Berbeda dengan teknik pencarian konvensional, tahap awal pencarian dalam algoritma genetika dimulai dari himpunan penyelesaian acak (random) yang disebut populasi [3].

Populasi ini terdiri dari kromosom-kromosom. Setiap kromosom merupakan gambaran solusi atas pemecahan masalah. Populasi yang telah dipilih tersebut akan menghasilkan keturunan baru yang sifatnya diharapkan lebih baik dari populasi sebelumnya. Populasi yang baik sifatnya akan memiliki peluang untuk terus dikembangkan agar menghasilkan keturunan populasi yang lebih baik selanjutnya. Dengan demikian, solusi terbaik yang diinginkan dapat dicapai dengan terus mengulang proses pencarian keturunan.

Dalam proses tersebut, sebelum algoritma genetika dijalankan didefinisikan suatu fungsi fitness yang menyatakan tingkat keberhasilan sebuah populasi. Dengan melakukan perhitungan berdasarkan fungsi fitness, akan dapat ditentukan populasi yang akan dipertahankan untuk menghasilkan generasi selanjutnya. Proses ini biasa disebut sebagai proses seleksi. Proses ini merupakan salah satu tahap yang dirangkai dalam proses yang iteratif [4].

Proses lain yang termasuk pada rangkaian iterasi ini yaitu crossover. Pada proses ini, dilakukan persilangan atau perkawinan antar kromosom yang berada dalam satu generasi. Dengan demikian, kromosom yang terdapat pada populasi selanjutnya mewarisi sifat kedua induknya. Kromosom ini diharapkan bersifat lebih baik dibanding dengan generasi sebelumnya. Sedangkan proses mutasi merupakan proses diubahnya satu atau lebih nilai gen kromosom dalam satu populasi. Nilai gen tersebut akan digantikan dengan suatu nilai yang dipilih secara acak. Pada tahap ini, terdapat kemungkinan perubahan sifat di luar sifat induk pada keturunan yang dihasilkan.

\subsection{Canonical Genetic Algorithm}

Algoritma genetika adalah sebuah algoritma adaptif untuk menemukan solusi optimal menyeluruh untuk masalah optimasi. Canonical Genetic Algorithm (CGA) dikembangkan oleh Holland yang ditandai dengan representasi biner dari solusi individu, masalah sederhanacrossover bebas, operator mutasi dan aturan pemilihan proporsional [5]. Untuk lebih memahami CGA, dapat dilihat prosedur standar yang terdapat pada gambar 1 berikut. 
ISSN 2089-8673

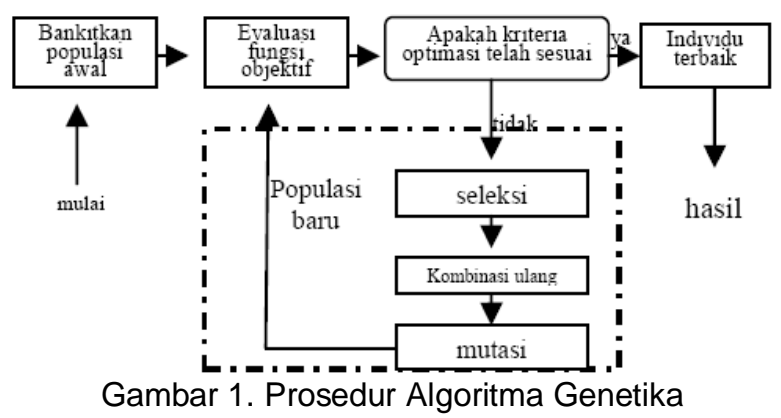

Anggota populasi adalah string atau kromosom, yang awalnya dipahami sebagai representasi biner dari vektor solusi. CGA memilih himpunan bagian yang menjadi solusi dari sebuah populasi yang dinamakan parent (orang tua), yang digabungkan untuk menghasilkan solusi baru yang dinamakan children (anak-anak) atau offspring. Aturan kombinasi untuk menghasilkan anak didasarkan pada gagasan genetik crossover, yang terdiri dari pertukaran tempat dari nilai solusi variabel tertentu. Pada suatu kondisi tertentu terjadi perubahan nilai acak yang disebut mutasi. Anak-anak yang dihasilkan oleh perkawinan orang tua dan yang lulus "tes bertahan hidup" kemudian akan tersedia untuk dipilih sebagai orang tua dari generasi berikutnya.

\section{III.Implementasi Perangkat Lunak}

Penggunaan piranti lunak dalam penelitian ini mengikuti tahapan-tahapan yang ada pada algoritma genetika secara umum. Yaitu seperti terlihat pada gambar 2 berikut.

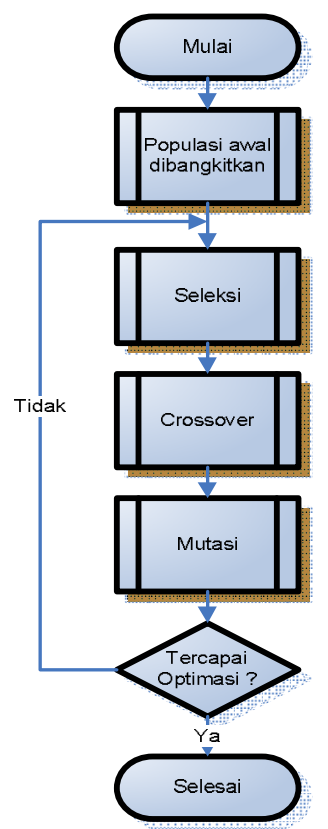

Gambar 2. Flowchart Algoritma Genetika dalam Perangkat Lunak

\subsection{Teknik Encoding}

Proses encoding adalah salah satu proses yang sulit dalam algoritma genetika. Hal ini disebabkan karena proses encoding untuk setiap permasalahan berbeda-beda karena tidak semua teknik encoding cocok untuk setiap permasalahan. Proses encoding menghasilkan 


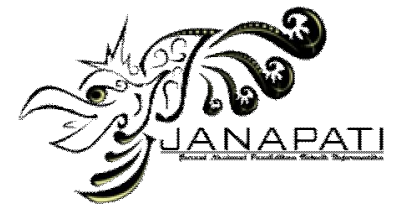

ISSN 2089-8673

Jurnal Nasional Pendidikan Teknik Informatika (JANAPATI) Volume 1, Nomor 3, Desember 2012

string yang kemudian disebut kromosom. String terdiri dari sekumpulan bit. Bit ini dikenal sebagai gen. Jadi satu kromosom terdiri dari sejumlah gen.

Ada bermacam-macam teknik encoding yang dapat dilakukan dalam algoritma genetika. Beberapa teknik-teknik encoding itu antara lain adalah binary encoding, permutation encoding, value encoding serta tree encoding. Teknik encoding yang digunakan pada penelitian ini adalah permutation encoding dan value encoding.

Pada permutation encoding, kromosom-kromosom adalah kumpulan angka yang mewakili posisi dalam sebuah rangkaian. Pada pencarian jalur distribusi ini, kromosom mewakili urutan kota sebagai jalur distribusi. Jadi apabila satu kromosom berbentuk sebagai berikut $P 1=$ $(\mathrm{X} 1, \mathrm{X} 2, \mathrm{X} 3, . ., \mathrm{Xn})$ berarti jalur distribusi bergerak dari kota bernomor $X 1$ ke $X 2$ dst hingga ke kota ke $X n$.

Sedangkan Pada value encoding, setiap kota tujuan distribusi diwakili oleh sebuah angka, dan angka tersebut merupakan sebuah gen yang ada pada sebuah kromosom. Setiap kromosom yang ada pada satu generasi merepresentasikan kombinasi jalur distribusi barang yang digunakan untuk mendapatkan hasil yang optimal.

Berikut ini adalah contoh kromosom pada persoalan ini : 1234 5, 34215,54321 , 3245 1. Itu berarti bahwa angka 1,2,3,4,5 adalah angka yang mewakili nama kota pada jalur distribusi dan urutan penulisan angka menunjukkan urutan kota pada jalur distribusi barangnya.

\subsection{Proses Seleksi}

Proses seleksi adalah proses yang memegang peranan penting dalam algoritma genetika. Proses seleksi ini digunakan agar hanya kromosom-kromosom yang berkualitas yang dapat melanjutkan peranannya dalam proses algoritma genetika berikutnya. Ada bermacammacam teknik untuk melakukan proses seleksi pada suatu permasalahan. Teknik seleksi yang akan digunakan tergantung pada permasalahan yang akan diselesaikan. Ada beberapa metode seleksi dari induk, diantaranya adalah Rank-based Fitness Assignment, Roulette Wheel Selection, Stochastic Universal Sampling, Local Selection, Truncation Selection, Tournament Selection [2].

Proses penyeleksian yang digunakan disini adalah Roulette Wheel Selection. Pada proses penyeleksian digunakan suatu parameter yang disebut kesesuaian atau fitness. Fitness digunakan untuk menentukan seberapa baik kromosom akan bertahan hidup. Penentuan berapa besar nilai fitness suatu kromosom berdasarkan fungsi fitness yang didefinisikan tersendiri. Untuk makalah ini maka fungsi fitness didefinisikan sebagai:

Fitness $=$ TotalJarak

Sebelumnya telah didapatkan jarak antar kota di jawa sebagai berikut pada Gambar 3. DAFTAR JARAK ANTAR KOTA DI PULAU JAWA

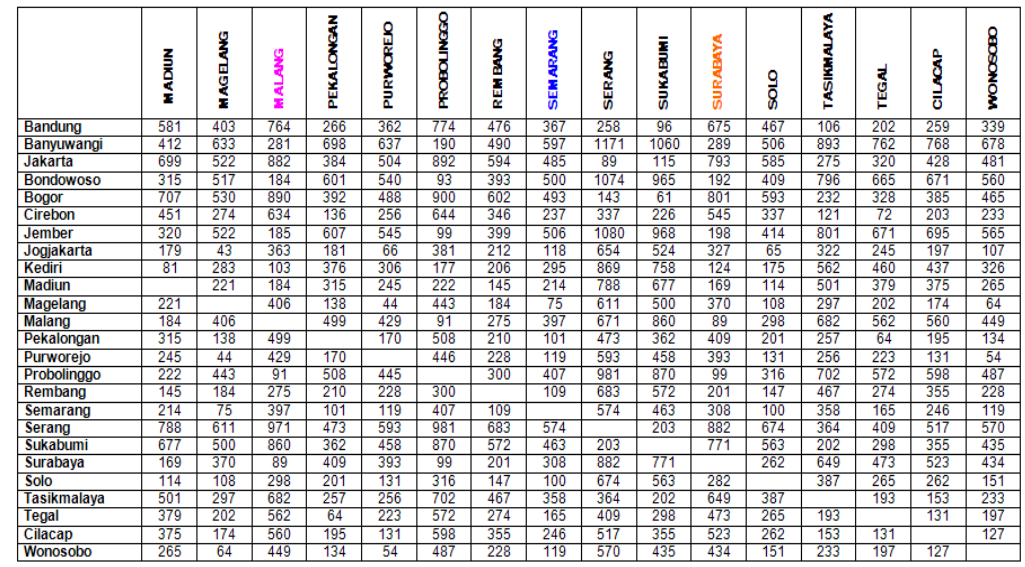

Gambar 3. Jarak antar Kota di Jawa 


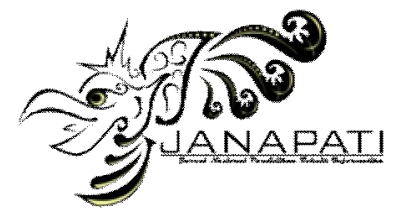

ISSN 2089-8673

Jurnal Nasional Pendidikan Teknik Informatika (JANAPATI) Volume 1, Nomor 3, Desember 2012

Dimisalkan jalur distribusi yang akan ditempuh adalah Kediri - Malang - Semarang Rembang - Solo. Kemudian dilakukan teknik encoding dengan menginisialisasi kota-kota tersebut dengan angka yaitu Kediri(1) - Malang(2) - Semarang(3) - Rembang(4) - Solo(5). Didapatkan gennya adalah Malang(2) - Semarang(3) - Rembang(4) - Solo(5), Kediri(1) tidak dimasukkan kedalam gen karena asumsinya adalah bahwa kota asal adalah juga merupakan kota akhir tujuan distribusi barang.

Kemudian misalkan ada enam populasi dalam satu generasi yaitu :

Kromosom[1] : [Malang - Rembang - Solo - Semarang] atau [B D E C] Kromosom[2] : [Rembang - Malang - Solo - Semarang] atau [D B E C] Kromosom[3] : [Semarang - Malang - Rembang - Solo] atau [C B D E] Kromosom[4] : [Solo - Malang - Semarang - Rembang] atau [E B C D] Kromosom[5] : [Solo - Semarang - Malang - Rembang] atau [E C B D] Kromosom[6] : [Semarang - Rembang - Solo - Malang] atau [C D E B]

Kemudian dihitung nilai fitnessnya :

Fitness[1] $\quad=A B+B D+D E+E C+C A=103+275+147+100+295=920$

Fitness[2] $\quad=A D+D B+B E+E C+C A=206+275+298+100+295=1174$

Fitness[3] $=A C+C B+B D+D E+E A=295+397+275+147+175=1289$

Fitness $[4] \quad=A E+E B+B C+C D+D A=175+298+397+109+206=1185$

Fitness $[5] \quad=A E+E C+C B+B D+D A=175+100+397+275+206=1153$

Fitness[6] $=A C+C D+D E+E B+B A=295+109+147+298+103=952$

Dari hasil diatas dicari kromosom dengan fitness yang lebih kecil dan kromosom tersebut akan mempunyai probabilitas lebih besar untuk terpilih kembali maka digunakan inverse. Dengan rumus :

$$
\mathrm{Q}[\mathrm{i}]=\frac{1}{\text { Fitness }[\mathrm{f}]} \text {. }
$$

$\mathrm{Q}[1]=1 / 920=0,001087$

$\mathrm{Q}[2]=1 / 1174=0,000852$

$\mathrm{Q}[3]=1 / 1289=0,000776$

$\mathrm{Q}[4]=1 / 1185=0,000844$

$\mathrm{Q}[5]=1 / 1153=0,000867$

$\mathrm{Q}[6]=1 / 952=0,00105$

Total $\mathrm{Q}[]=0,001087+0,000852+0,000776+0,000844+0,000867+0,00105$

Total Q[] = 0,005476

Kemudian setelah menemukan nilai Q-nya, dilanjutkan dengan mencari probabilitasnya, untuk tahu kromosom mana yang terpilih sebagai generasi baru.

Rumus probabilitasnya :

$$
\mathrm{P}[\mathrm{i}]=\frac{\left.Q_{\mathrm{i}} \mathrm{i}\right]}{\mathrm{TotalQ}}
$$

$P[1]=0,001087 / 0,005476=0,199$

$\mathrm{P}[2]=0,000852 / 0,005476=0,156$

$P[3]=0,000776 / 0,005476=0,142$

$P[4]=0,000844 / 0,005476=0,154$

$P[5]=0,000867 / 0,005476=0,158$

$P[6]=0,00105 / 0,005476=0,192$

Terlihat bahwa kromosom 1 mempunyai fitness terkecil sehingga probabilitas untuk terpilih pada generasi selanjutnya lebih besar dari pada kromosom yang lain. Proses seleksi dengan menggunakan Roulette Wheel Selection mempunyai tahap-tahap sebagai berikut:

1. [Sum] : Jumlahkan semua nilai probabilitasnya $\rightarrow C$

2. [Select] : Men-generate bilangan random dengan intervel $(0-C) \rightarrow R$

3. [Loop] : Membandingkan nilai $\mathrm{R}$ dan $\mathrm{C}$, Jika $\mathrm{R}[\mathrm{k}]<\mathrm{C}[\mathrm{k}]$ maka kromosom ke-k sebagai induk, selain itu pilih kromosom ke-k sebagai induk dengan syarat $\mathrm{C}[\mathrm{k}-1]<\mathrm{R}[\mathrm{k}]<\mathrm{C}[\mathrm{k}$ 


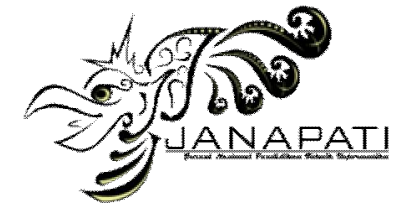

Jurnal Nasional Pendidikan Teknik Informatika (JANAPATI) Volume 1, Nomor 3, Desember 2012

Looping atau proses memutar Roulette Wheel nya dilakukan sebanyak jumlah kromosom (enam) untuk mendapatkan nilai randomnya.

Mencari nilai kumulatif dari probe
$\mathrm{C}[1]=0,199$
$\mathrm{C}[2]=0,199+0,156=0,355$
$\mathrm{C}[3]=0,355+0,142=0,497$
$\mathrm{C}[4]=0,497+0,154=0,651$
$\mathrm{C}[5]=0,651+0,158=0,809$
$\mathrm{C}[6]=0,809+0,192=1,001$

Kemudian nilai random $(R)$ nya :

$\mathrm{R}[1]=0,314$

$\mathrm{R}[2]=0,111$

$\mathrm{R}[3]=0,342$

$\mathrm{R}[4]=0,743$

$\mathrm{R}[5]=0,521$

$\mathrm{R}[6]=0,411$

Setelah perbandingan dilakukan, di dapatkan populasi yang terbaru : Kromosom[1] : [2] :[Rembang - Malang - Solo - Semarang] atau [D B E C] Kromosom[2]:[1] :[Malang - Rembang - Solo - Semarang] atau [B D E C] Kromosom[3] : [3] :[Semarang - Malang - Rembang - Solo] atau [C B D E] Kromosom[4] : [5] : [Solo - Semarang - Malang - Rembang] atau [E C B D] Kromosom[5] : [4] :[Solo - Malang - Semarang - Rembang] atau [E B C D] Kromosom[6] : [6] : [Semarang - Rembang - Solo - Malang] atau [C D E B]

\subsection{Proses Rekombinasi atau Crossover}

Proses rekombinasi atau yang lebih dikenal dengan nama proses crossover adalah menyilangkan dua kromosom sehingga membentuk kromosom baru yang harapannya lebih baik dari pada induknya. Tidak semua kromosom pada suatu populasi akan mengalami proses rekombinasi. Kemungkinan suatu kromosom mengalami proses rekombinasi didasarkan pada probabilitas crossover (PC) yang telah ditentukan terlebih dahulu. Probabilitas crossover menyatakan peluang suatu kromosom akan mengalami crossover. Ada beberapa teknik rekombinasi yang dapat digunakan untuk menyelesaikan masalah seperti ini, antara lain adalah partially mapped crossover (PMX), order crossover dan cycle crossover [6].

Teknik rekombinasi yang digunakan adalah teknik order crossover. Order crossover (OX) diperkenalkan oleh Davis. Teknik ini diawali dengan membangkitkan dua bilangan acak. Kemudian gen yang berada diantara kedua bilangan acak akan disalin ke offspring dengan posisi yang sama. Langkah berikutnya untuk mendapatkan offspring pertama adalah mengurutkan gen yang berada pada parent kedua dengan urutan gen yang berada pada posisi setelah bilangan acak kedua diikuti dengan gen yang berada pada posisi sebelum bilangan acak pertama dan diakhiri dengan gen yang berada pada posisi diantara kedua bilangan acak. Kemudian gen yang telah diurutkan tersebut dibandingkan dengan offspring pertama. Apabila gen tersebut ada pada offspring kedua maka abaikan gen tersebut dari urutan itu. Kemudian masukkan urutan yang baru saja didapat pada offspring dengan cara memasukkan urutan gen pada posisi setelah bilangan acak kedua terlebih dahulu dan sisanya dimasukkan pada posisi sebelum bilangan acak pertama. Begitu juga untuk menghasikan offspring kedua.

Misal kita tentukan PC $=50 \%$, maka diharapkan dalam 1 generasi ada $50 \%$ * 6 kromosom = 3 kromosom dari populasi mengalami crossover.

Sebelumnya, bangkitkan bilangan acak R sebanyak jumlah populasi yaitu 6 kali.

$\mathrm{R}[1]=0,541$

$R[2]=0,211$

$R[3]=0,302$ 


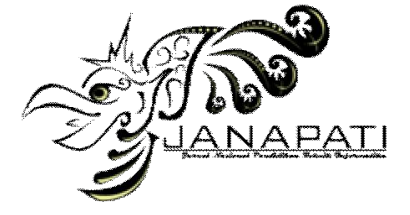

Jurnal Nasional Pendidikan Teknik Informatika (JANAPATI) Volume 1, Nomor 3, Desember 2012

$\mathrm{R}[4]=0,877$

$\mathrm{R}[5]=0,771$

$\mathrm{R}[6]=0,131$

Kemudian dicari dengan kategori Kromosom ke-k yang dipilih sebagai induk jika $R[k]$ < pc. Maka yang akan dijadikan induk adalah kromosom[2], kromosom[3], dan kromosom[6]. Proses selanjutnya adalah menentukan posisi crossover. Dilakukan dengan membangkitkan bilangan acak antara 1 sampai dengan panjang kromosom-1. $(4-1=3)$

Dimisalkan bilangan acak untuk 3 kromosom induk yang akan di-crossover :

$\mathrm{C}[2]=2$

$\mathrm{C}[3]=1$

$\mathrm{C}[6]=2$

Misal diperoleh bilangan acaknya 2, maka gen yang ke-2 pada kromosom induk pertama diambil kemudian ditukar dengan gen pada kromosom induk kedua yang belum ada pada induk pertama dengan tetap memperhatikan urutannya.

Proses crossover :

Kromosom[2] $=$ Kromosom[2] $><$ Kromosom[3] $=[$ B D E C] $><[C$ B D E] $=[B$ D C E]

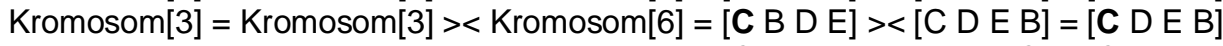

Kromosom[6] $=$ Kromosom[6] $><$ Kromosom[2] $=[$ C D E B] $><[B$ D E C] $=[$ C D B E]

Sehingga didapatkan populasi setelah di-crossover :

Kromosom[1] $=$ [D B E C]

Kromosom[2] $=[B$ D C E]

Kromosom[3] $=[$ C D E B]

Kromosom[4] $=[$ E C B D $]$

Kromosom[5] $=[$ [E B C D]

Kromosom[6] $=[$ C D B E]

\subsection{Proses Mutasi}

Proses mutasi ini dilakukan setelah proses rekombinasi dengan cara memilih kromosom yang akan dimutasi secara acak, dan kemudian menentukan titik mutasi pada kromosom tersebut secara acak pula. Banyaknya kromosom yang akan mengalami mutasi dihitung berdasarkan probabilitas mutasi yang telah ditentukan terlebih dahulu.

Apabila probabilitas mutasi adalah 100\% maka semua kromosom yang ada pada populasi tersebut akan mengalami mutasi. Sebaliknya, jika probabilitas mutasi yang digunakan adalah 0\% maka tidak ada kromosom yang mengalami mutasi pada populasi tersebut.

Ada bermacam-macam teknik mutasi yang dapat digunakan untuk menyelesaikan suatu masalah dengan algoritma genetika. Seperti pada teknik rekombinasi, teknik mutasi juga dirancang untuk digunakan pada suatu masalah yang spesifik sehingga tidak setiap teknik mutasi dapat diterapkan pada suatu masalah yang akan diselesaikan. Selain itu, teknik mutasi yang digunakan juga harus sesuai dengan teknik encoding yang digunakan untuk menyelesaikan permasalahan tersebut. Beberapa teknik mutasi yang dapat digunakan dalam penyelesaian masalah ini adalah inversion mutation, insertion mutation, swapping mutation. dan reciprocal mutation.

Pada kasus ini skema mutasi yang digunakan adalah swapping mutation. Jumlah kromosom yang mengalami mutasi dalam satu populasi ditentukan oleh parameter mutation rate (PM). Proses mutasi dilakukan dengan cara menukar gen yang dipilih secara acak dengan gen sesudahnya. Jika gen tersebut berada di akhir kromosom, maka ditukar dengan gen yang pertama.

Pertama dihitung dahulu panjang total gen yang ada pada satu populasi:

Panjang Total Gen = jumlah gen dalam 1 kromosom * jumlah Kromosom

Panjang total gen $=4$ * 6

Panjang total gen $=24$ 


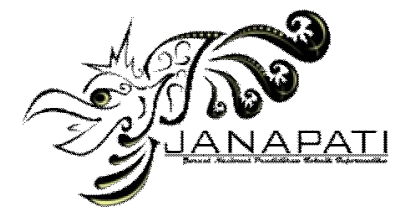

ISSN 2089-8673

Jurnal Nasional Pendidikan Teknik Informatika (JANAPATI)

Volume 1, Nomor 3, Desember 2012

Untuk memilih posisi gen yang mengalami mutasi dilakukan dengan membangkitkan bilangan acak antara 1 - Panjang total gen yaitu 1- 24. Misal, Ditentukan PM $=20 \%$. Maka jumlah gen yang akan dimutasi adalah $=0,2{ }^{*} 24=4,8=5$. Kemudian 5 buah posisi gen yang akan dimutasi, setelah diacak adalah posisi 3, 7, 10, 20, 24.

Kromosom hasil crossover:

Kromosom[1] $=[$ D B E C]

Kromosom[2] $=[$ [B D C E]

Kromosom[3] $=[$ C D E B]

Kromosom[4] $=[$ E C B D]

Kromosom[5] $=[$ E B C D ]

Kromosom $[6]=[C$ D B E $]$

Proses mutasi :

Kromosom[1] $=[$ D B C E]

Kromosom[2] $=[B$ D E C $]$

Kromosom[3] $=[$ C E D B]

Kromosom[4] $=[$ E C B D]

Kromosom[5] $=[$ D B C E]

Kromosom[6] $=[$ [E D B C $]$

Setelah proses ini selesai maka satu generasi telah selesai pula di-generate dengan algoritma genetika. Sebelumnya ditentukan dulu kapan proses algoritma genetika ini akan berhenti. Ada beberapa kondisi untuk mengeceknya yaitu jika diperoleh nilai fitness yang terendah yang tidak berubah atau kita tentukan akan di generate hingga generasi ke $-\mathrm{N}$.

Kemudian dicari lagi nilai Fitnessnya. Nilai fitness setelah 1 generasi adalah:

Fitness[1] $=\mathrm{AD}+\mathrm{DB}+\mathrm{BC}+\mathrm{CE}+\mathrm{EA}=206+275+397+100+175=1153$

Fitness[2] $=A B+B D+D E+E C+C A=103+275+147+100+295=920$

Fitness[3] $=\mathrm{AC}+\mathrm{CE}+\mathrm{ED}+\mathrm{DB}+\mathrm{BA}=295+100+147+275+103=920$

Fitness $[4]=A E+E C+C B+B D+D A=175+100+397+275+206=1153$

Fitness $[5]=A D+D B+B C+C E+E A=206+275+397+100+175=1153$

Fitness[6] $=\mathrm{AE}+\mathrm{ED}+\mathrm{DB}+\mathrm{BC}+\mathrm{CA}=175+147+275+397+295=1289$

IV. Skenario Uji Coba Aplikasi

Skenario uji coba aplikasi dilakukan sebanyak tiga kali, dengan pola distribusi awal yang sama (Kediri-Malang-Semarang-Rembang-Solo). Skenario yang pertama yaitu dengan menggunakan PC (Crossover Probability) dan PM (Mutation Rate) yang rendah, skenario yang kedua dengan menggunakan PC (Crossover Probability) dan PM (Mutation Rate) yang sedang dan skenario yang ketiga dengan menggunakan PC (Crossover Probability) dan PM (Mutation Rate) yang tinggi.

\subsection{Skenario Pertama}

Pada Gambar 4 berikut ini adalah inisialisasi data awal yang menghasilkan rute distribusi dengan nilai fitness terendah 931 (A) dengan rute distribusi: Kediri-Solo-RembangSemarang-Malang (B). 


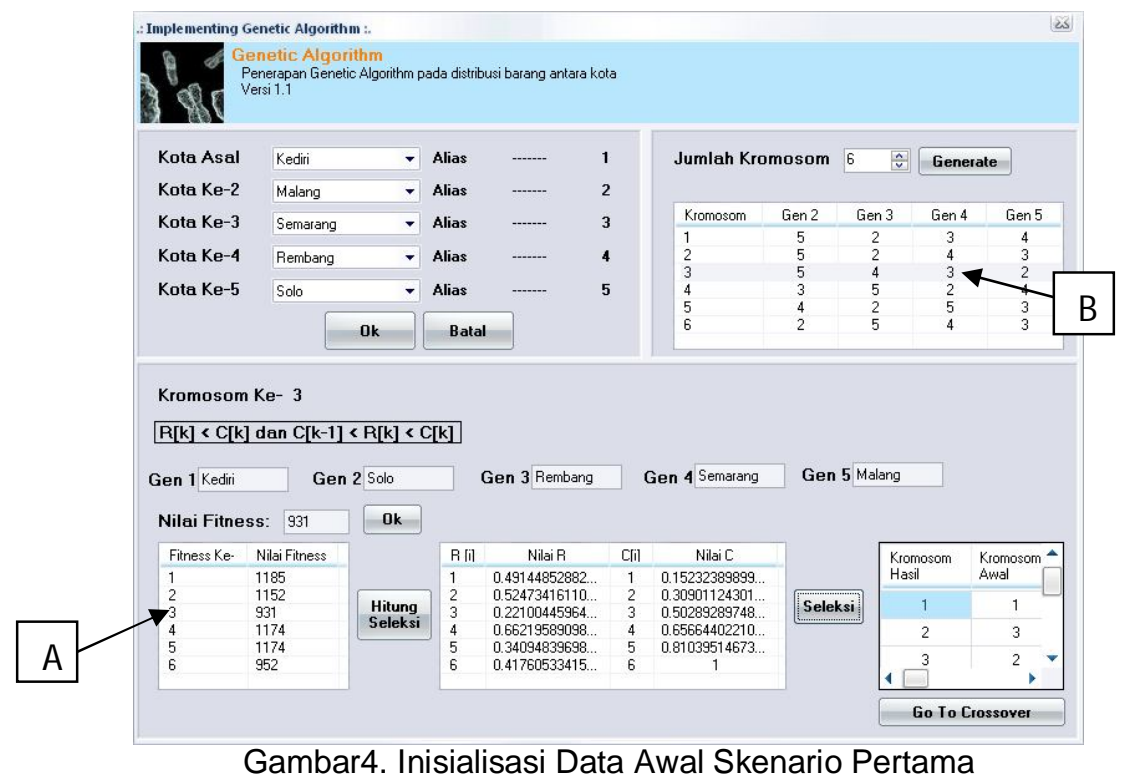

Proses seleksi tersebut menghasilkan perubahan urutan kromosom yang dapat dilihat pada Gambar 5 dan Gambar 6 berikut.

\begin{tabular}{|c|c|}
\hline $\begin{array}{l}\text { Kromosom } \\
\text { Hasil }\end{array}$ & $\begin{array}{l}\text { Kromosom } \\
\text { Awal }\end{array}$ \\
\hline 1 & 1 \\
\hline 2 & 3 \\
\hline 3 & 2 \\
\hline
\end{tabular}

Gambar 5. Perubahan Urutan Kromosom 1-3

\begin{tabular}{|c|c|}
\hline $\begin{array}{l}\text { Kromosom } \\
\text { Hasil }\end{array}$ & $\begin{array}{l}\text { Kromosom } \\
\text { Awal }\end{array}$ \\
\hline 4 & 5 \\
\hline 5 & 4 \\
\hline 6 & 6 \\
\hline$\square$ & \\
\hline
\end{tabular}

Gambar 6. Perubahan Uratan Kromosom 4-6

Inputan untuk PC pada skenario pertama ini adalah 20, yang menghasilkan 2 induk crossover yang dapat dilihat pada Gambar 7 berikut. 
ISSN 2089-8673

Jurnal Nasional Pendidikan Teknik Informatika (JANAPATI)

Volume 1, Nomor 3, Desember 2012

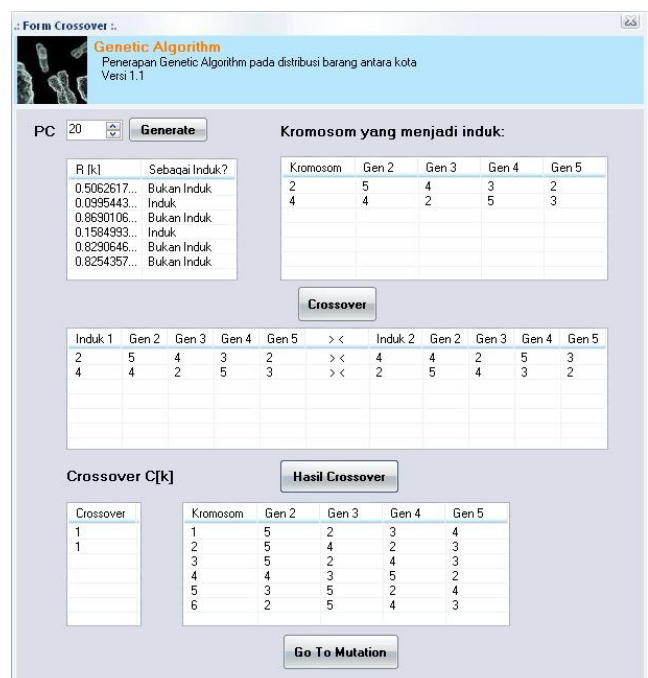

Gambar 7. Crossover Skenario Pertama

Inputan untuk PM pada skenario pertama ini adalah 25 , yang menghasilkan posisi mutasi sebanyak 5 yang dapat dilihat pada Gambar 8 berikut.

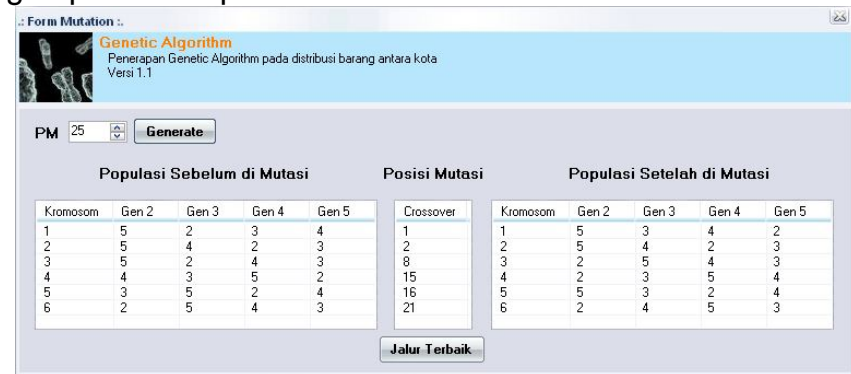

Gambar 8. Mutasi Skenario Pertama

Hasil akhir setelah dilakukan proses seleksi, crossover dan mutasi dapat dilihat pada Gambar 9 berikut.

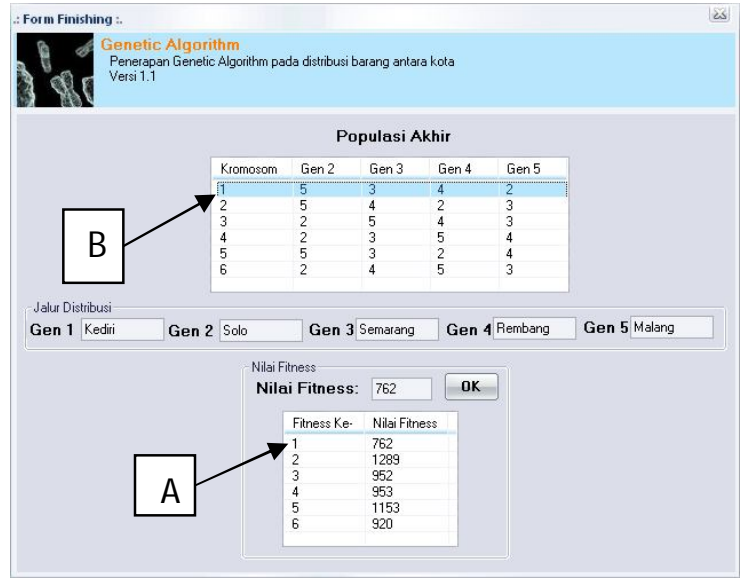

Gambar 9. Hasil Akhir Skenario Pertama 
Dari hasil akhir ini dapat dilihat bahwa kromosom yang pertama dengan nilai fitness terendah yaitu 762 (A), dengan rute distribusi: Kediri-Solo-Semarang-Rembang-Malang (B). Dari proses pada skenario pertama ini dapat disimpulkan bahwa dengan nilai PC dan PM yang rendah $(<50)$ menghasilkan rute distribusi dengan nilai fitness yang lebih rendah daripada nilai fitness pada tahap inisialisasi data awal.

\subsection{Skenario Kedua}

Pada Gambar 10 berikut ini adalah inisialisasi data awal yang menghasilkan rute distribusi dengan nilai fitness terendah 762 (A) dengan rute distribusi: Kediri-Solo-SemarangRembang-Malang (B).

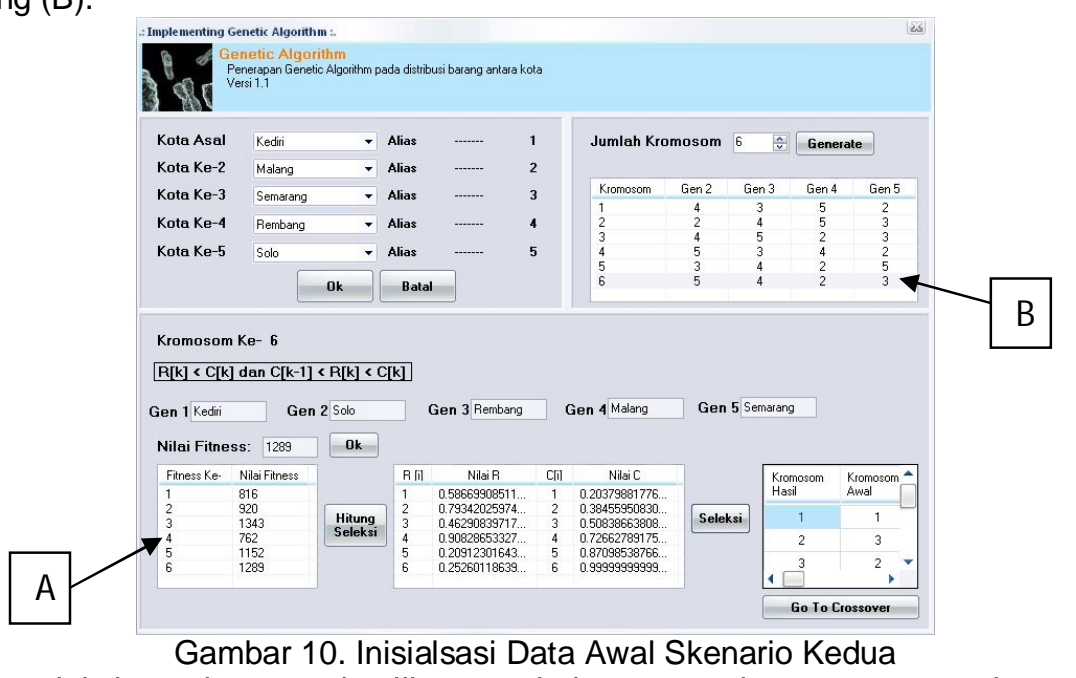

Proses seleksi tersebut menghasilkan perubahan urutan kromosom yang dapat dilihat pada Gambar 11 dan Gambar 12 berikut.

$$
\begin{array}{|c|c|}
\hline \begin{array}{l}
\text { Kromosom } \\
\text { Hasil }
\end{array} & \begin{array}{l}
\text { Kromosom } \\
\text { Awal }
\end{array} \\
\hline 1 & 1 \\
\hline 2 & 3 \\
\hline 3 & 2 \\
\hline & 2 \\
\hline
\end{array}
$$

Gambar 11. Perubahan Urutan Kromosom 1-3

$$
\begin{array}{|c|cc|}
\hline \begin{array}{l}
\text { Kromosom } \\
\text { Hasil }
\end{array} & \begin{array}{l}
\text { Kromosom } \\
\text { Awwal }
\end{array} \\
\hline 4 & 5 & \\
\hline 5 & 4 & \\
\hline 6 & 6 & \\
\hline 4 & & \multicolumn{2}{|c|}{} \\
\hline
\end{array}
$$

Gambar 12. Perubahan Urutan Kromosom 4-6

Inputan untuk PC pada skenario kedua ini adalah 50, yang menghasilkan 2 induk crossover yang dapat dilihat pada Gambar 13 berikut. 


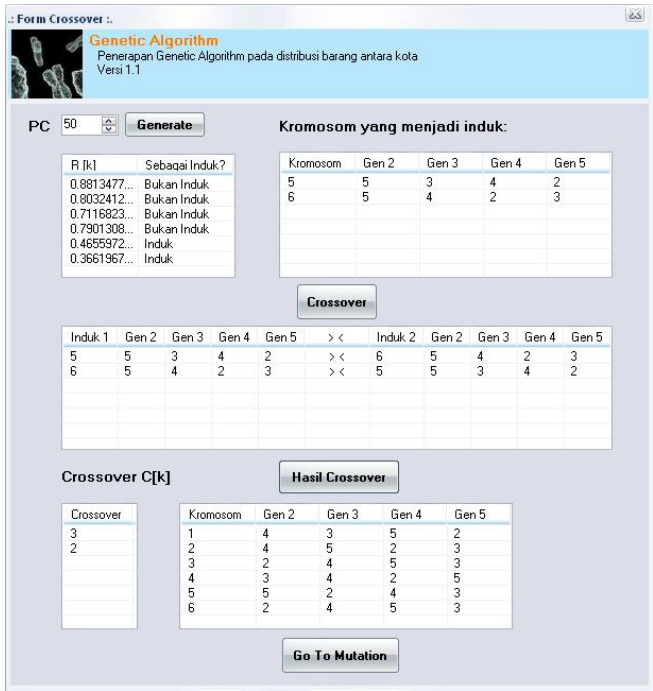

Gambar 13. Crossover Skenario Kedua

Inputan untuk PM pada skenario kedua ini adalah 50, yang menghasilkan posisi mutasi sebanyak 12 yang dapat dilihat pada Gambar 14 berikut.

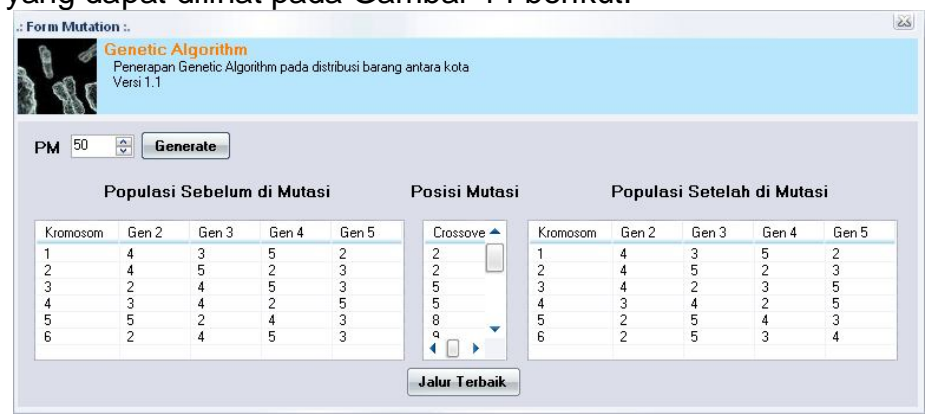

Gambar 14. Mutasi Skenario Kedua

Hasil akhir setelah dilakukan proses seleksi, crossover dan mutasi dapat dilihat pada Gambar 15 berikut.

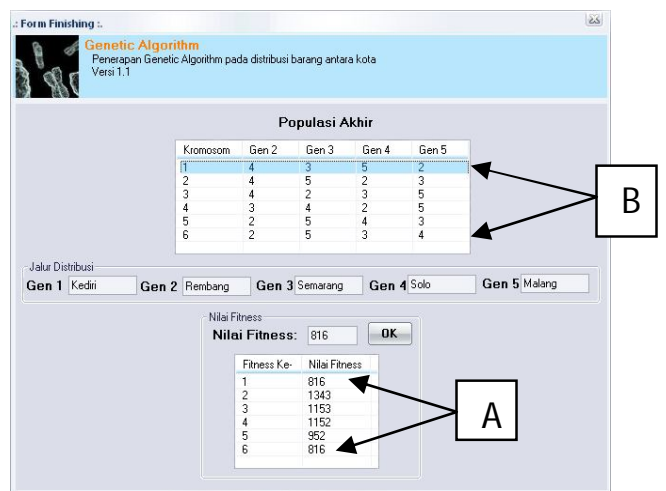

Gambar 15. Hasil Akhir Skenario Kedua

Dari hasil akhir ini dapat dilihat bahwa kromosom yang pertama dan keenam dengan nilai fitness terendah yaitu 816 (A), dengan rute distribusi: (Kromosom1) Kediri-RembangSemarang-Solo-Malang dan (Kromosom6) Kediri-Malang-Solo-Semarang-Rembang (B). Dari proses pada skenario pertama ini dapat disimpulkan bahwa dengan nilai PC dan PM yang sedang $(=50)$ menghasilkan rute distribusi dengan nilai fitness yang lebih tinggi daripada nilai 
fitness pada tahap inisialisasi data awal dan ada kemungkinan dua kromosom dengan rute yang berbeda memiliki nilai fitness yang sama.

\subsection{Skenario Ketiga}

Pada Gambar 16 berikut ini adalah inisialisasi data awal yang menghasilkan rute distribusi dengan nilai fitness terendah 762 (A) dengan rute distribusi: Kediri-Solo-SemarangRembang-Malang (B).

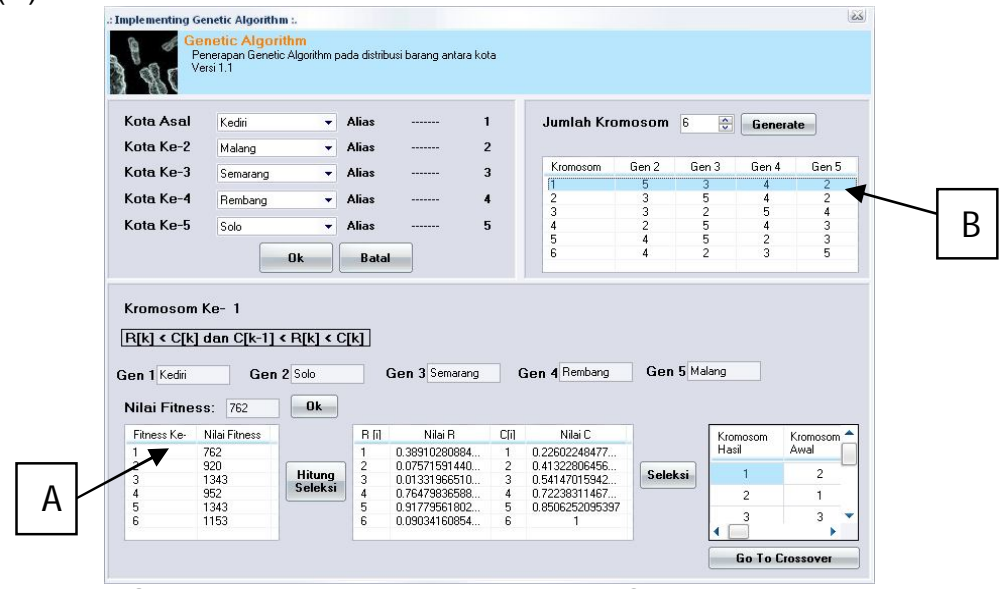

Gambar 16. Inisialisasi Data Awal Skenario Ketiga

Proses seleksi tersebut menghasilkan perubahan urutan kromosom yang dapat dilihat pada Gambar 17 dan Gambar 18 berikut.

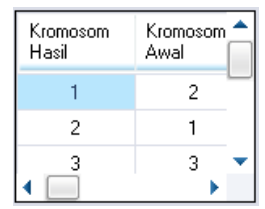

Gambar 17. Perubahan Urutan Kromosom 1-3

\begin{tabular}{|c|c|}
\hline $\begin{array}{l}\text { Kromosom } \\
\text { Hasil }\end{array}$ & $\begin{array}{l}\text { Kromosom - } \\
\text { Awal }\end{array}$ \\
\hline 4 & 4 \\
\hline 5 & 6 \\
\hline 4 & $5>$ \\
\hline
\end{tabular}

Gambar 18. Perubahan Urutan Kromosom 4-6

Inputan untuk PC pada skenario ketiga ini adalah 85, yang menghasilkan 6 induk (semua kromosom merupakan induk crossover) crossover yang dapat dilihat pada Gambar 19 berikut. 
ISSN 2089-8673

Jurnal Nasional Pendidikan Teknik Informatika (JANAPATI)

Volume 1, Nomor 3, Desember 2012

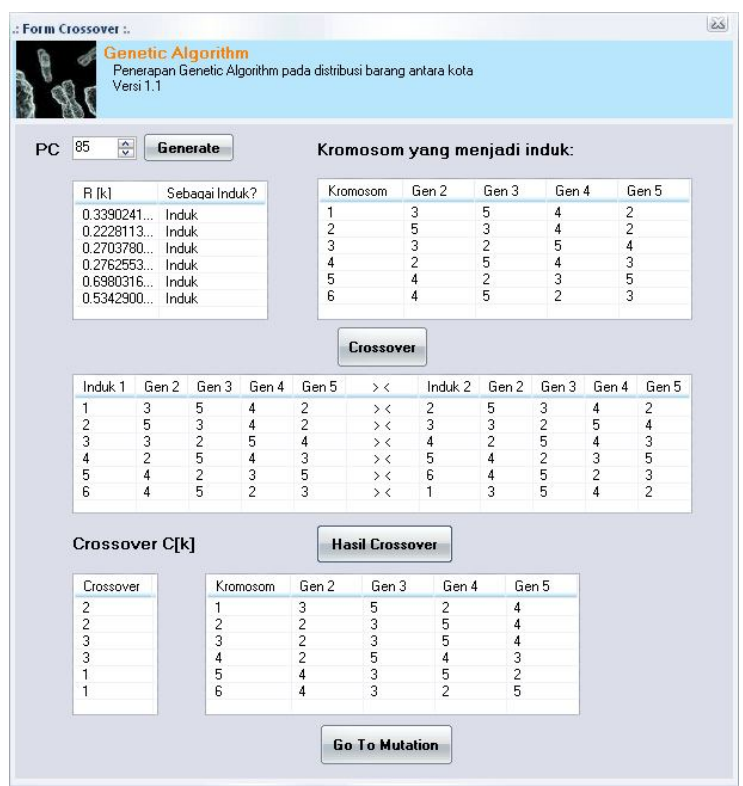

Gambar 19. Crossover Skenario Ketiga

Inputan untuk PM pada skenario ketiga ini adalah 85, yang menghasilkan posisi mutasi sebanyak 20 yang dapat dilihat pada Gambar 20 berikut.

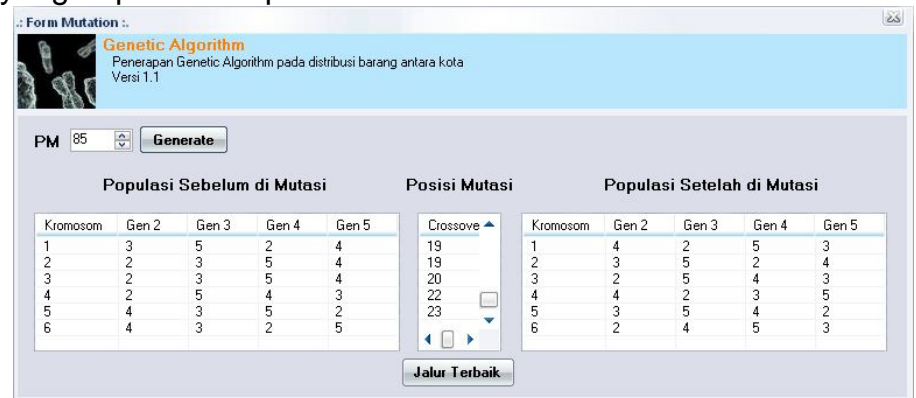

Gambar 20. Mutasi Skenario Ketiga

Hasil akhir setelah dilakukan proses seleksi, crossover dan mutasi dapat dilihat pada Gambar 21 berikut.

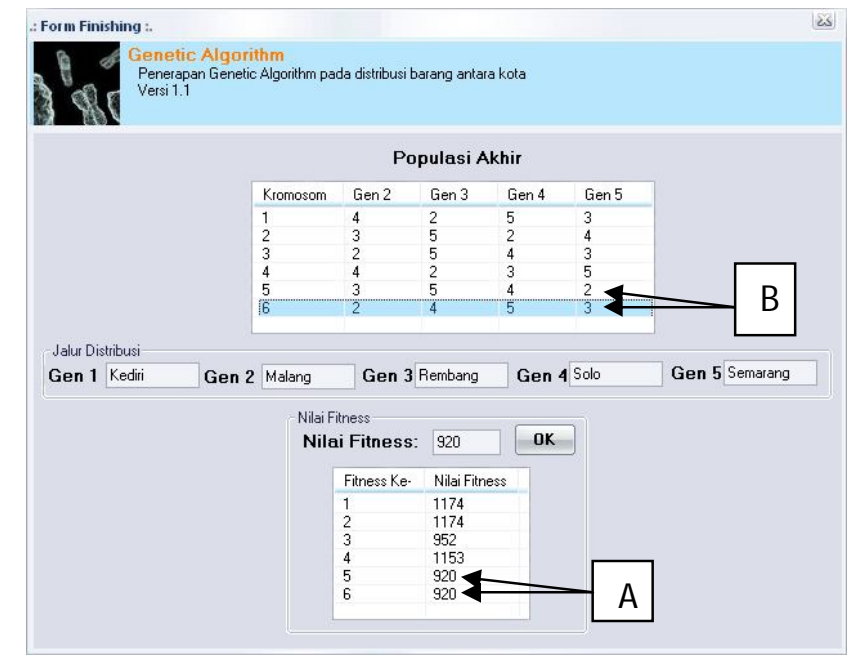




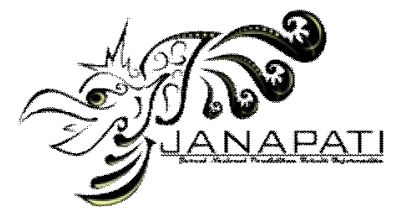

Jurnal Nasional Pendidikan Teknik Informatika (JANAPATI)
Volume 1, Nomor 3, Desember 2012

Gambar 21. Hasil Akhir Skenario Ketiga

Dari hasil akhir ini dapat dilihat bahwa kromosom yang kelima dan keenam dengan nilai fitness terendah yaitu 920 (A), dengan rute distribusi: (Kromosom 5) Kediri-SemarangSolo-Rembang-Malang dan (Kromosom 6) Kediri-Malang-Rembang-Solo-Semarang (B). Dari proses pada skenario pertama ini dapat disimpulkan bahwa dengan nilai PC dan PM yang tinggi (>50) menghasilkan rute distribusi dengan nilai fitness yang lebih tinggi daripada nilai fitness pada tahap inisialisasi data awal dan ada kemungkinan dua kromosom dengan rute yang berbeda memiliki nilai fitness yang sama.

\section{Kesimpulan}

Beberapa kesimpulan yang dapat diambil setelah mempelajari mengenai algoritma genetika dan mencoba mengaplikasikannya ke perangkat lunak adalah sebagai berikut: Algoritma genetika merupakan suatu algoritma yang menggunakan parameter dan bilangan random (acak), sehingga pada setiap perhitungan menghasilkan hasil perhitungan yang berbeda. Algoritma genetika bagus untuk menyelesaikan persoalan optimasi suatu rute namun harus ditentukan kriteria optimasi yang diinginkan dalam bentuk nilai PC dan PM yang sesuai. Nilai PC dan PM yang rendah bagus untuk menghasilkan nilai fitness yang terendah (rute terbaik), namun sulit untuk menentukan nilai terendah tersebut dikarenakan proses crossover dan mutasi bergantung pada bilangan random (acak) yang dibandingkan dengan inputan PC dan PM tersebut. Dapat juga disimpulkan bahwa dengan menerapkan algoritma genetika untuk kasus penentuan jalur terpendek adalah efektif. Terbukti pada skenario pertama dengan penentuan $\mathrm{PC}$ dan $\mathrm{PM}<50$ didapatkan nilai fitness yang lebih rendah yang berarti bahwa rute tersebut adalah jalur terpendek. Hasil pemrosesan tergantung pada hasil generasi kromosom pada saat awal dijalankan. Jika pada saat generasi awal kromosom tersebut sudah didapatkan nilai fitness yang lebih rendah daripada rute yang diinputkan, maka sebaiknya ditentukan bahwa hal itu adalah kriteria untuk pemrosesan algoritma genetika ini berhenti. Jika pemrosesan tetap dijalankan dengan seleksi, crossover maupun mutasi maka kemungkinan besar pemrosesan algoritma genetika untuk menemukan jalur terpendek akan gagal. Hal tersebut terbukti pada skenario kedua dan ketiga, yang menghasilkan kromosom dengan nilai fitness yang lebih tinggi dibandingkan dengan kromosom pada saat inisialisasi data awal.

\section{Daftar Pustaka}

[1] Liu, Y., Zhou, C., Guo, D., Wang., K., Pang, W., Zhai, Y., 2010, A Decision Support System Using Soft Computing for Modern International Container Transportation Services, Applied Soft Computing, Volume 10, Issue 4, September 2010, pp. 1087-1095

[2] Kusumadewi, Sri, 2003, Artificial Intelligence (Teknik dan Aplikasinya), Yogyakarta: Graha IImu.

[3] Lumbantobing, H., Hidayatno, A., Darjat, 2011, Penerapan Algoritma Genetika pada Perencanaan Lintas Kendaraan, Undergraduate Thesis, Universitas Diponegoro

[4] Fitrah, A., Zaky, A., Fitrasani, 2006, Penerapan Algoritma Genetika pada Persoalan Pedagang Keliling (TSP), Sekolah Tinggi Elektro Dan Informatika ITB.

[5] Cao, Y. J., Wu, Q. H., 1999, Teaching Genetic Algorithm Using Matlab, International Journal Electrical Engineering Education, Vol. 36, pp. 139-153.

[6] Lukas, S., Anwar, T., Yuliani, W., 2005, Penerapan Algoritma Genetika untuk Traveling Salesmen Problem dengan Menggunakan Metode Order Crossover dan Insertion Mutation, Seminar Nasional Aplikasi Teknologi Informasi. 